\title{
BMJ Open The efficacy of sodium bicarbonate in preventing contrast-induced nephropathy in patients with pre-existing renal insufficiency: a meta-analysis
}

\author{
Bin Zhang, ${ }^{1,2}$ Long Liang, ${ }^{1,2}$ Wenbo Chen, ${ }^{1}$ Changhong Liang, ${ }^{1}$ Shuixing Zhang ${ }^{1}$
}

To cite: Zhang B, Liang L, Chen $\mathrm{Wb}$, et al. The efficacy of sodium bicarbonate in preventing contrast-induced nephropathy in patients with pre-existing renal insufficiency: a meta-analysis. BMJ Open 2015;5:e006989. doi:10.1136/ bmjopen-2014-006989

- Prepublication history for this paper is available online. To view these files please visit the journal online (http://dx.doi.org/10.1136/ bmjopen-2014-006989).

Received 23 October 2014 Revised 28 January 2015 Accepted 29 January 2015

CrossMark

\footnotetext{
${ }^{1}$ Department of Radiology, Guangdong Academy of Medical Sciences/Guangdong General Hospital, Graduate College, Guangzhou, Guangdong Province, China ${ }^{2}$ Southern Medical University, Guangzhou, Guangdong Province, China
}

Correspondence to Dr Shuixing Zhang; shui7515@hotmail.com

\section{ABSTRACT}

Objective: The aim of this meta-analysis was to explore the efficacy of sodium bicarbonate in preventing contrast-induced nephropathy (CIN).

Methods: We searched PubMed, Medline and the Cochrane Library from 1 January 2004 to 1 August 2014. The effect estimate was expressed as a pooled OR with $95 \% \mathrm{Cl}$, using the fixed-effects or randomeffects model.

Results: 20 randomised controlled trials $(n=4280)$ were identified. Hydration with sodium bicarbonate was associated with a significant decrease in CIN among patients with pre-existing renal insufficiency (OR $0.67,95 \% \mathrm{Cl} 0.47$ to $0.96 ; p=0.027$ ). However, moderate heterogeneity was noted across trials $\left(I^{2}=48 \% ; p=0.008\right)$. Subgroup analyses indicated a better effect of sodium bicarbonate in studies using low-0smolar (OR $0.59,95 \% \mathrm{Cl} 0.37$ to 0.93 ; $\mathrm{p}=0.024)$ compared with iso-osmolar contrast agents (OR $0.76,95 \% \mathrm{Cl} 0.43$ to $1.34 ; p=0.351$ ). The odds of CIN with sodium bicarbonate were lower in studies including only patients undergoing emergency (OR $0.16,95 \% \mathrm{Cl} 0.05$ to $0.51 ; p=0.002$ ) compared with elective procedures (OR $0.76,95 \% \mathrm{Cl}$ 0.54 to $1.06 ; p=0.105)$. Sodium bicarbonate was more beneficial in patients given a bolus injection before procedures $(\mathrm{OR} 0.15,95 \% \mathrm{Cl} 0.04$ to 0.54 ; $\mathrm{p}=0.004$ ) compared with continuous infusion (OR $0.75,95 \% \mathrm{Cl} 0.53$ to $1.05 ; p=0.091$ ). Sodium bicarbonate plus $\mathrm{N}$-acetylcysteine (OR $0.17,95 \% \mathrm{Cl}$ 0.04 to $0.79 ; p=0.024)$ was better than sodium bicarbonate alone (OR $0.71,95 \% \mathrm{Cl} 0.48$ to 1.03 ; $\mathrm{p}=0.071$ ). The effect of sodium bicarbonate was considered greater in papers published before $(O R$ $0.19,95 \% \mathrm{Cl} 0.09$ to $0.41 ; p=0.000)$ compared with after 2008 (OR $0.85,95 \% \mathrm{Cl} 0.62$ to $1.16 ; \mathrm{p}=0.302$ ). However, no significant differences were found in mortality (OR $0.69,95 \% \mathrm{Cl} 0.36$ to $1.32 ; \mathrm{p}=0.263$ ) or requirement for dialysis (OR $1.08,95 \% \mathrm{Cl} 0.52$ to 2.25; $\mathrm{p}=0.841$ ).

Conclusions: Sodium bicarbonate is effective in preventing CIN among patients with pre-existing renal insufficiency. However, it fails to lower the risks of dialysis and mortality and therefore cannot improve the clinical prognosis of patients with CIN.

\section{Strengths and limitations of this study}

In this updated meta-analysis, we demonstrated that pre-procedural hydration with sodium bicarbonate was associated with a significant decrease in the incidence of contrast-induced nephropathy (CIN) among patients with pre-existing renal insufficiency.

- We found that sodium bicarbonate did not lower the risks of dialysis and mortality and so did not improve the clinical prognosis of patients with CIN.

- The new Jadad scale was used to assess the quality of reviewed articles.

- Publication bias and moderate heterogeneity were found among the included trials.

\section{INTRODUCTION}

Contrast-induced nephropathy (CIN) is the third leading cause of in-hospital acute kidney injury, ${ }^{1-3}$ which is a serious complication of angiographic procedures resulting from the administration of contrast media. Although the definition of CIN varies, it is usually defined as an increase in the serum creatinine (Scr) level of $25 \%$ or an increase of $0.5 \mathrm{mg} / \mathrm{dL}$ (or $44 \mu \mathrm{mol} / \mathrm{L}$ ) from baseline within $48-72 \mathrm{~h}$ of contrast exposure. CIN results in increased morbidity, prolonged hospital stay and increased healthcare expenditure, and is associated with higher mortality. ${ }^{4}$

The incidence of CIN in the general population is low, but increases exponentially in patients with high-risk factors, such as pre-existing renal insufficiency or diabetes mellitus. ${ }^{5}$ In a recent study, $21.7 \%$ of a group with pre-existing chronic renal insufficiency and $6.3 \%$ of a group without pre-existing chronic renal insufficiency developed CIN. ${ }^{6}$ Thus, baseline renal insufficiency may be a significant predisposing factor for CIN.

Sodium bicarbonate-based hydration has been proposed to prevent CIN. Some recent studies suggested that sodium bicarbonate 
had a more protective effect compared with sodium chloride for the prevention of CIN, while others did not. ${ }^{7-17}$ Although most previous meta-analyses supported the use of sodium bicarbonate, there may have been publication bias and none of the studies focused on patients with pre-existing renal insufficiency. Therefore, we performed this meta-analysis to determine the efficacy of sodium bicarbonate in preventing CIN among patients with renal insufficiency undergoing procedures needing contrast agents. In addition, differences in the requirement for dialysis and post-procedural death between the two groups in various studies were compared in this analysis.

\section{METHODS}

\section{Data sources and searches}

We searched PubMed, Medline and the Cochrane Library from 1 January 2004 to 1 August 2014 without language limitations. Medical subject headings and keyword searches included the terms 'contrast induced nephropathy', 'sodium bicarbonate', 'sodium chloride', 'saline', 'acute kidney injury' and 'renal failure'. The reference lists of selected articles were reviewed for other potentially relevant citations. In addition, the top 50 citations for each identified relevant study were searched by using the 'related articles' function of PubMed.

\section{Study selection}

Two investigators (BZ and LL) independently reviewed the titles and abstracts of all studies to identify those of interest. The online publications identified from the preliminary selection were then reviewed in full text to assess if the studies met the following inclusion criteria:

1. Participants: adult patients ( $\geq 18$ years) with preexisting renal insufficiency, defined as an Scr concentration of $>1.1 \mathrm{mg} / \mathrm{dL}$ or estimated glomerular filtration rate (eGFR) of $<60 \mathrm{~mL} / \mathrm{min}^{18}$ or creatinine clearance rate of $<60 \mathrm{~mL} / \mathrm{min}^{9}$

2. Comparison: sodium bicarbonate (and/or Nacetylcysteine) versus saline (and/or N-acetylcysteine)

3. Outcome: relevance to the primary outcome of this study which is the incidence of CIN, while the secondary outcomes include the requirement for dialysis and mortality

4. Type of study: only randomised controlled trials (RCTs) were considered.

Exclusion criteria were as follows:

1. Insufficient data for extraction and analysis

2. Using N-acetylcysteine in only one arm.

Reviewers were not blinded to study authors or outcomes. The final inclusion of studies was based on the agreement of both reviewers.

\section{Data extraction and quality assessment}

Two independent reviewers (BZ and WBC) extracted relevant information from the literature including baseline clinical characteristics (mean age, percentage of males, risk factors other than renal insufficiency, baseline Scr, eGFR, procedures, interventions, type and volume of contrast media, hydration regimen, definition of CIN) (table 1), and data on primary (the incidence of CIN) and secondary outcomes (ie, the requirement for dialysis and mortality). CIN was defined variously in the studies, but was usually described as an absolute or relative increase in Scr level. Three studies defined CIN as a rise in Scr of $25 \%$ or more within 2-5 days of contrast exposure, ${ }^{12} 1920$ while 13 studies regarded CIN as a rise of $0.5 \mathrm{mg} / \mathrm{dL}$ or a $25 \%$ increase in Scr within 2-4 days of contrast exposure. Two studies defined CIN as an increase in Scr of $0.5 \mathrm{mg} / \mathrm{dL}$ after the procedures. ${ }^{9} 15$ However, the remaining two trials differed from the above: CIN was defined in one trial as a decrease in eGFR of $25 \%$ within 4 days, and in the other as an absolute increase in Scr of at least $0.3 \mathrm{mg} / \mathrm{dL}$ or $50 \%$ or urine output of $<0.5 \mathrm{~mL} / \mathrm{kg} / \mathrm{h}(>6 \mathrm{~h})$ within 5 days. ${ }^{8} 17$ We assessed the quality of articles using the new Jadad scale after they were reviewed (table 2).

\section{Data synthesis and analysis}

Data from included studies were combined and expressed as pooled ORs with 95\% CIs. All analyses were performed on an 'intention-to-treat' basis. Initially, a fixed-effects model (Mantel-Haenzel method) was used in this meta-analysis. We evaluated heterogeneity across studies with Cochrane's $\mathrm{Q}$ test and $\mathrm{I}^{2}$ statistics. If $\mathrm{p}<0.10$, statistically significant heterogeneity was considered to be present. The $\mathrm{I}^{2}$ statistic was used to quantify the magnitude of heterogeneity, with values of $0-30 \%, 31-50 \%$ and $>50 \%$ representing mild, moderate and substantial heterogeneity, respectively. The outcome of fixed-effects model analysis demonstrated statistical heterogeneity, so we selected the random-effects model (Dersimonian and Laird method).

In light of the clinical and statistical heterogeneity across studies, subgroup analyses using the randomeffects model were performed to assess the effect of sodium bicarbonate in various conditions, such as lowosmolar versus iso-osmolar contrast agent, emergency versus elective procedures, articles published before versus after 2008, and continuous versus bolus infusion of sodium bicarbonate (table 3). An influence analysis was carried out to evaluate how robust the pooled estimator was after individual studies were removed one at a time (figure 4). An individual study was suspected of exerting excessive influence if the point estimate of its omitted analysis lay outside the $95 \%$ CI of the summary analysis. Publication bias was assessed using Begg's funnel plot and Egger's regression asymmetry test (figure 5). All statistical analyses were performed using STATA software, V.12.0 (Stata Corp LP, College Station, Texas, USA).

\section{RESULTS}

A total of 837 articles were reviewed and the 20 studies meeting the inclusion criteria were included in the study (figure 1). 


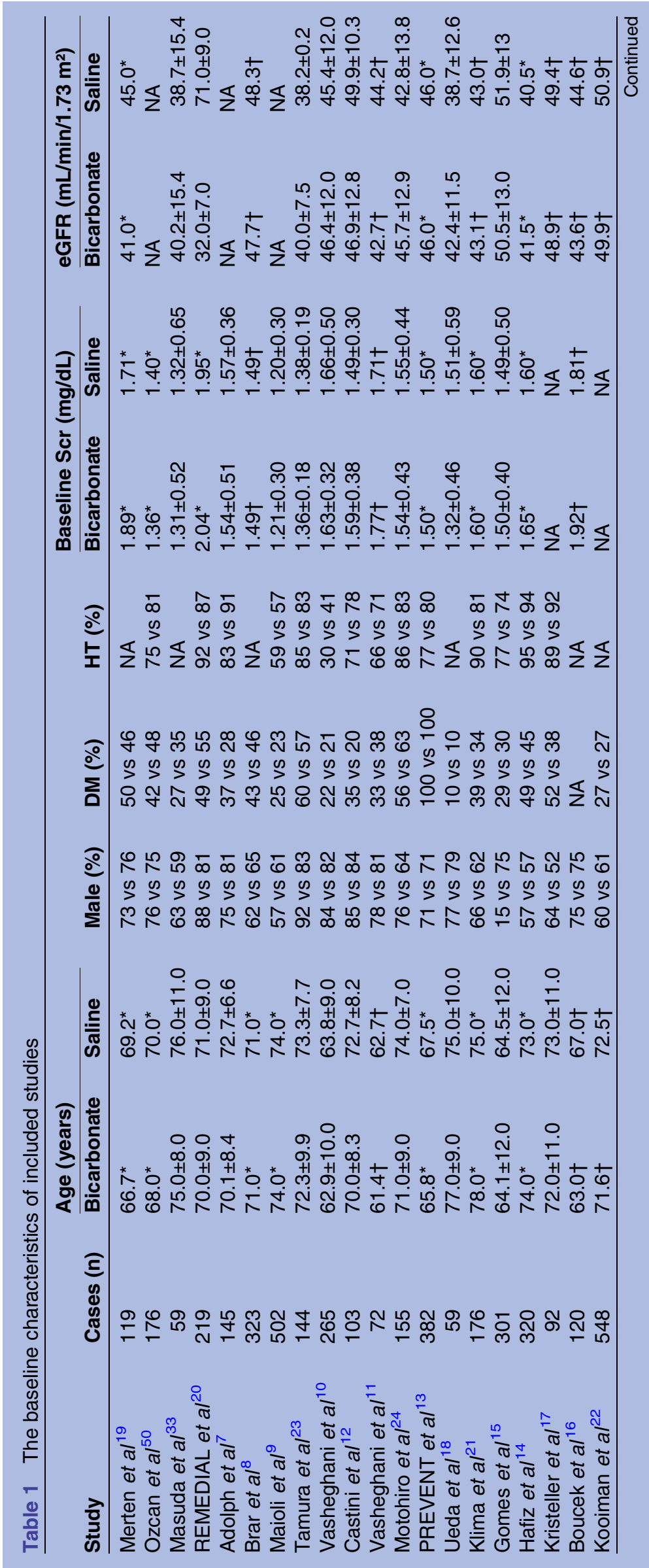




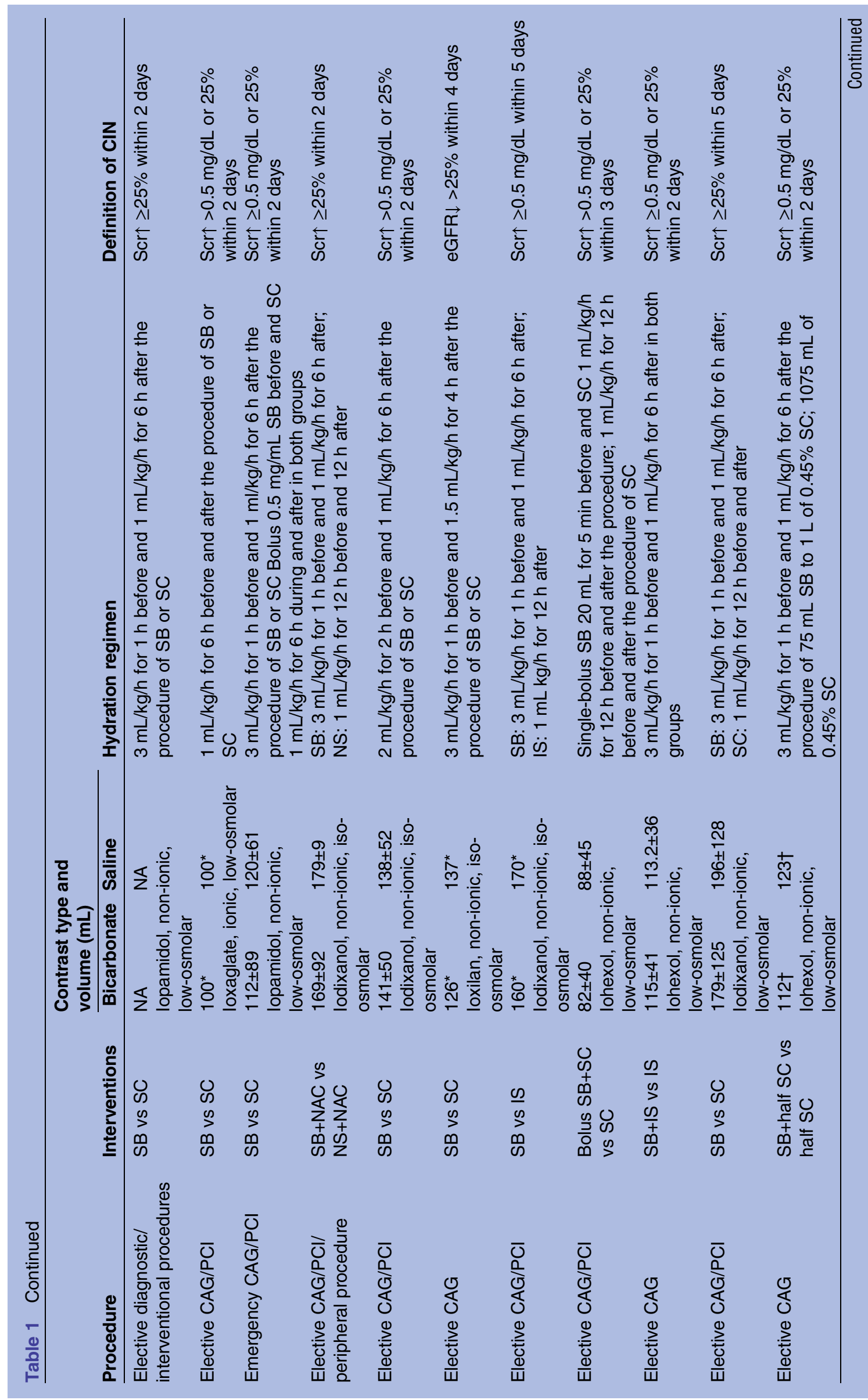




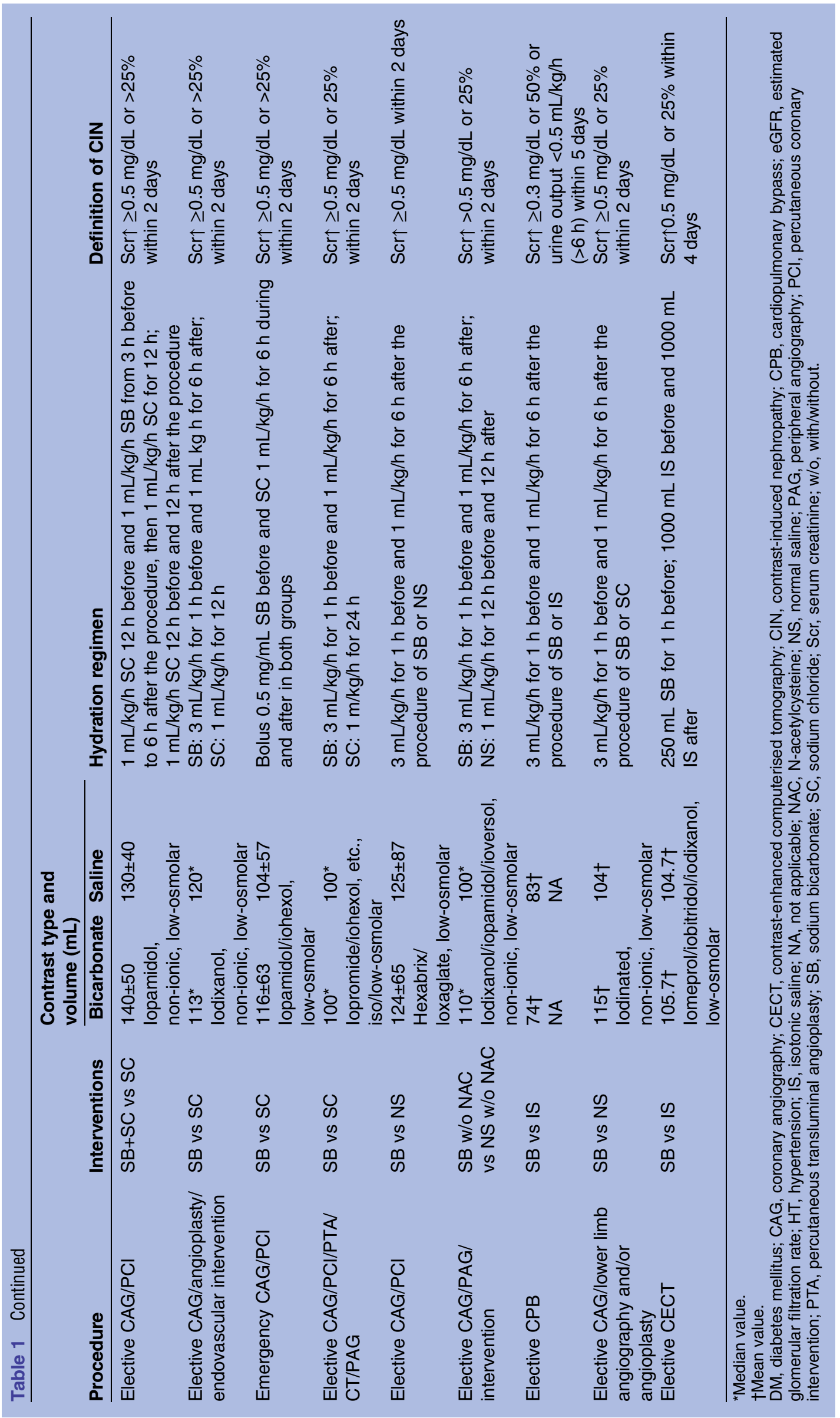




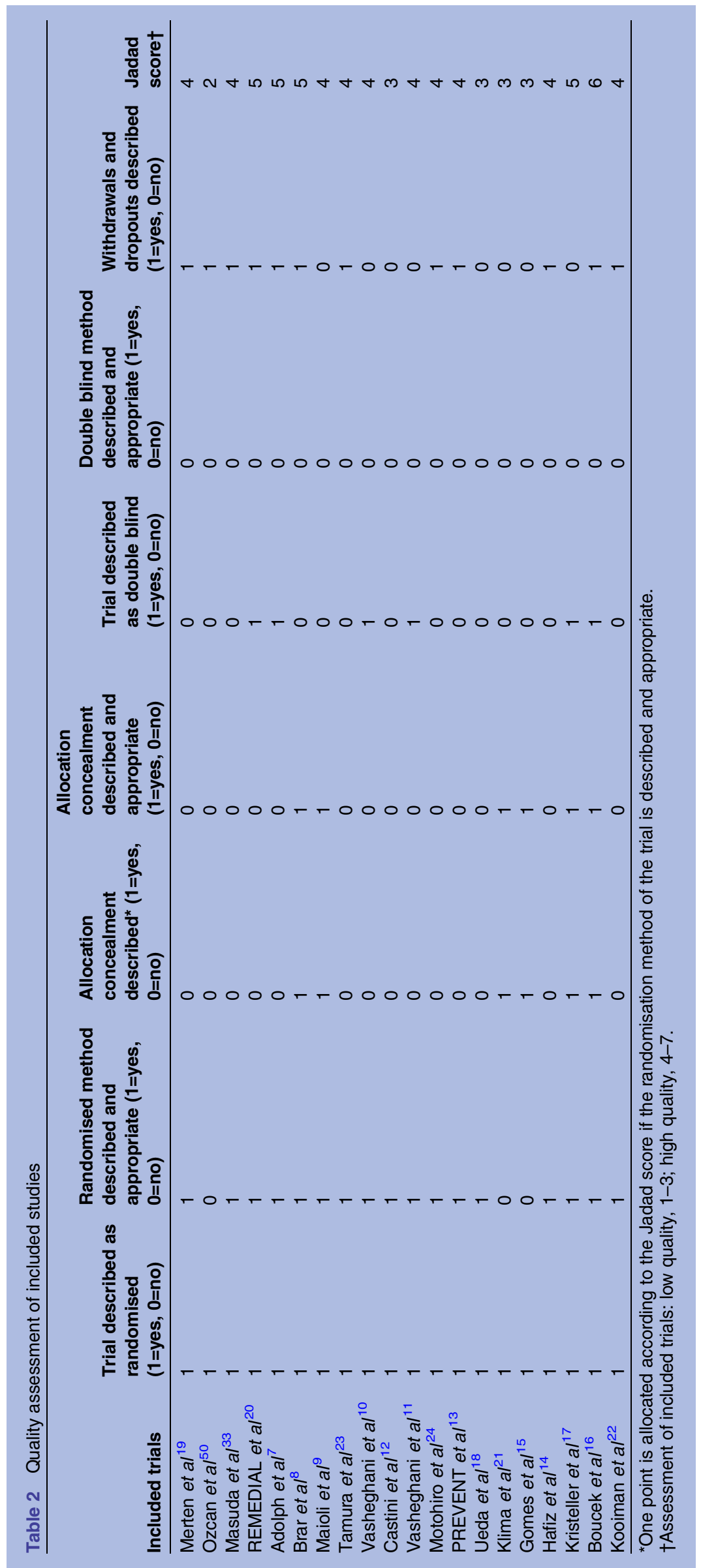


Table 3 Subgroup analyses used to assess the effect of sodium bicarbonate in various conditions

\begin{tabular}{|c|c|c|c|c|}
\hline Subgroups & Trials/patients & OR $(95 \% \mathrm{Cl})$ & Test for overall effect & Heterogeneity \\
\hline \multicolumn{5}{|l|}{ Type of contrast } \\
\hline Low-osmolar & $14 / 2823$ & $0.59(0.37$ to 0.93$)$ & $Z=2.26(p=0.024)$ & $\chi^{2}=26.61, d f=13(p=0.014),\left.\right|^{2}=51 \%$ \\
\hline Iso-osmolar & $4 / 1189$ & $0.76(0.43$ to 1.34$)$ & $Z=0.93(p=0.351)$ & $\chi^{2}=4.67, d f=3(p=0.198), l^{2}=36 \%$ \\
\hline \multicolumn{5}{|l|}{ Setting } \\
\hline Elective & $18 / 4162$ & $0.76(0.54$ to 1.06$)$ & $Z=1.62(p=0.105)$ & $\chi^{2}=29.54, d f=17(p=0.030), I^{2}=43 \%$ \\
\hline Emergency & 2/118 & $0.16(0.05$ to 0.51$)$ & $\mathrm{Z}=3.11(\mathrm{p}=0.002)$ & $\chi^{2}=0.07, d f=1(p=0.784),\left.\right|^{2}=0 \%$ \\
\hline \multicolumn{5}{|c|}{ Using NAC or not } \\
\hline Use & $1 / 219$ & $0.17(0.04$ to 0.79$)$ & $Z=2.26(p=0.024)$ & Not applicable \\
\hline Non-use & $18 / 3741$ & $0.71(0.48$ to 1.03$)$ & $Z=1.80(p=0.071)$ & $\chi^{2}=33.13, d f=17(p=0.011), l^{2}=49 \%$ \\
\hline \multicolumn{5}{|l|}{ Publication year } \\
\hline Before 2008 & $4 / 573$ & 0.19 (0.09 to 0.41$)$ & $Z=4.26(p=0.000)$ & $\chi^{2}=1.06, d f=10(p=0.788), l^{2}=0 \%$ \\
\hline After 2008 & $16 / 3707$ & $0.85(0.62$ to 1.16$)$ & $Z=1.03(p=0.302)$ & $\chi^{2}=22.13, d f=15(p=0.105), l^{2}=32 \%$ \\
\hline \multicolumn{5}{|c|}{ Manner of administration } \\
\hline Continuous & $18 / 4077$ & $0.75(0.53$ to 1.05$)$ & $Z=1.69(p=0.091)$ & $\chi^{2}=30.21, d f=17(p=0.025), I^{2}=44 \%$ \\
\hline Bolus & $2 / 203$ & 0.15 (0.04 to 0.54$)$ & $Z=2.90(p=0.004)$ & $\chi^{2}=0.23, d f=1(p=0.632), l^{2}=0 \%$ \\
\hline
\end{tabular}

A detailed description of the baseline characteristics of the included studies is given in table 1. Patients in most studies underwent coronary angiography or interventional procedures. There were also seven studies which examined peripheral procedures, angioplasty, cardiopulmonary bypass and CT. ${ }^{8} 1819$ 21-24 The sodium bicarbonate hydration regimen in 13 studies was as described by Merten et al and consisted of sodium bicarbonate infusion at a rate of $3 \mathrm{~mL} / \mathrm{kg} / \mathrm{h}$ for $1 \mathrm{~h}$ before and $1 \mathrm{~mL} / \mathrm{kg} / \mathrm{h}$ for $6 \mathrm{~h}$ after the procedure.

\section{Primary outcome}

CIN occurred in 158 of 2130 patients who received sodium bicarbonate compared with 217 of 2150 patients who received saline, demonstrating a lower overall incidence of CIN in the sodium bicarbonate group (figure 2). The pooled OR was 0.67 (95\% CI 0.47 to 0.96 ; $\mathrm{p}=0.027$ ), also in favour of sodium bicarbonate (figure 2).

However, moderate heterogeneity $\left(\mathrm{I}^{2}=48 \% ; \mathrm{p}=0.008\right)$ across studies was found (figure 2). Therefore, subgroup analyses were conducted using a random-effects model and showed a more pronounced effect of sodium bicarbonate in studies using low-osmolar contrast media (OR $0.59,95 \%$ CI 0.37 to 0.93 ; $\mathrm{p}=0.024$ ) (table 3 ). Similarly, subgroup analysis by setting suggested a lower incidence of CIN with sodium bicarbonate in studies of patients undergoing emergency procedures (OR 0.16, 95\% CI 0.05 to $0.51 ; p=0.002$ ) (table 3 ). The effect of sodium
Figure 1 Flow diagram of included studies. NAC, $\mathrm{N}$-acetylcysteine.

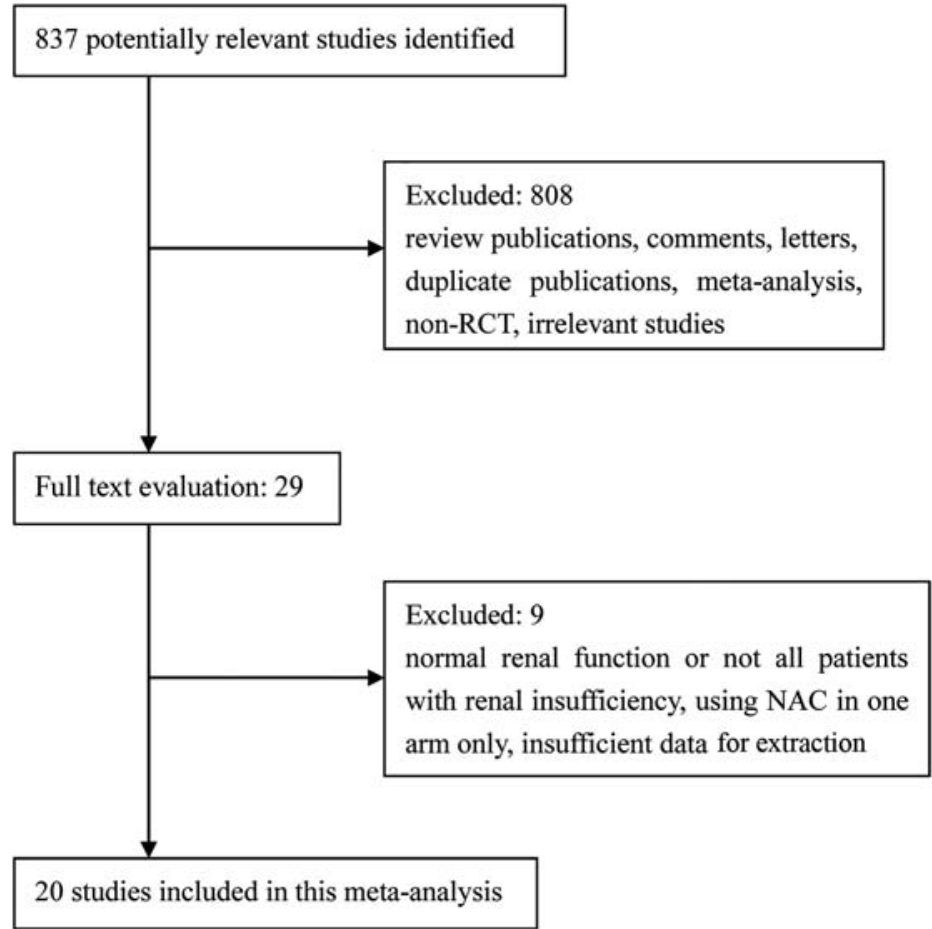




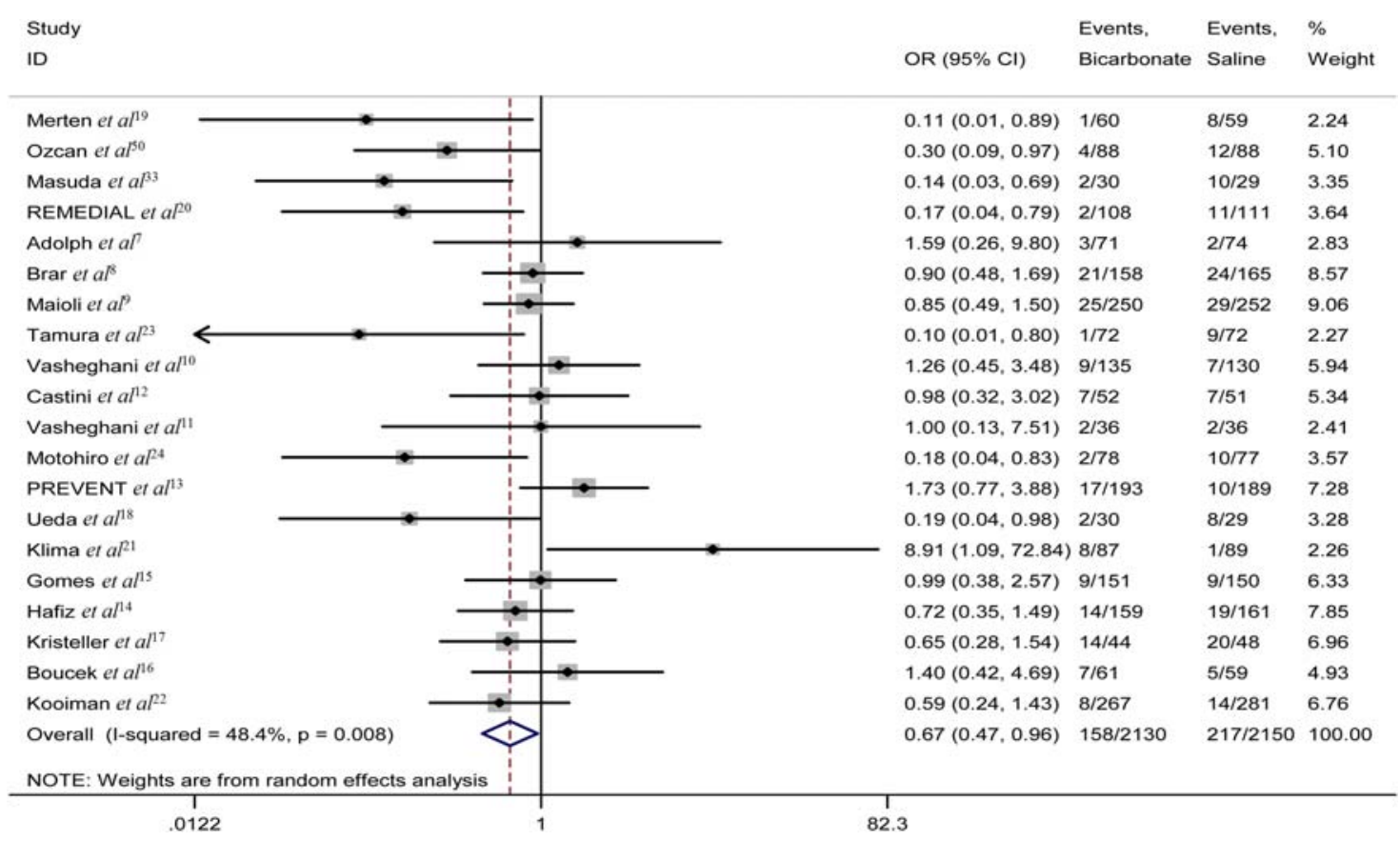

Figure 2 The forest plot of ORs of contrast-induced nephropathy.

bicarbonate was considered greater in articles published before 2008 (OR $0.19,95 \%$ CI 0.09 to 0.41 ; p $<0.001$ ) (table 3). Subgroup analysis based on the method of sodium bicarbonate administration indicated a better effect in patients given a bolus injection (OR 0.15, 95\% CI 0.04 to $0.54 ; \mathrm{p}=0.004$ ) (table 3 ). Sodium bicarbonate in combination with N-acetylcysteine (NAC) was better at preventing CIN (OR $0.17,95 \%$ CI 0.04 to 0.79 ; $\mathrm{p}=0.024) \quad$ (table 3).

Influence analysis showed that no individual study had an excessive influence on the overall estimate ORs or 95\% CIs (figure 4 ).

Begg's funnel plot and Egger's test $(p=0.396)$ implied there was no significant publication bias in this study (figure 5).

\section{Secondary outcomes}

\section{The requirement for dialysis}

The requirement for dialysis was described in 17 studies $(n=3633)$. In eight of these studies, no dialysis was carried out in either group. ${ }^{11} 12151618192224$ Overall, 14 of 1809 patients treated with sodium bicarbonate compared with 13 of 1824 patients treated with saline underwent dialysis. No statistically significant difference was observed (OR 1.08, 95\% CI 0.52 to 2.25; $\mathrm{p}=0.841$ ) (figure 3A). Nonetheless, the OR for the requirement for dialysis suggested that sodium bicarbonate was not better than saline in reducing the number of dialysis events.

\section{Mortality}

Post-procedural death was described in 12 studies $(n=2559)$. No deaths were reported in either group in six of these studies. ${ }^{11} 1314162324$ There were 15 deaths in 1279 patients treated with sodium bicarbonate and 22 in 1280 patients treated with saline. Although there was no significant difference between the two arms (OR $0.69,95 \%$ CI 0.36 to $1.32 ; \mathrm{p}=0.263$ ) (figure $3 \mathrm{~B}$ ), a trend toward lower mortality risk was found in the sodium bicarbonate arm compared with the saline arm.

\section{DISCUSSION}

Although CIN is generally regarded as a transient decline in renal function after contrast procedures, it cannot be regarded as a benign complication ${ }^{25}{ }^{26}$ as it accounts for $12 \%$ of all cases of acute renal failure. ${ }^{27}$ In an observational study, $0.8 \%$ of patients undergoing coronary angiography or interventional procedures started dialysis and $13 \%$ of them needed permanent dialysis. ${ }^{28}$ Furthermore, the development of CIN is associated with longer hospital stay, increased morbidity and mortality, and higher financial cost.

Various patient- and procedure-related risk factors may contribute to $\mathrm{CIN}{ }^{29}$ Pre-existing renal insufficiency and diabetes mellitus are the two main patientrelated risk factors. Renal insufficiency was usually defined as a decrease in eGFR, and since the eGFR has to fall by $50 \%$ before a rise in Scr occurs, an elevated Scr level was used as the cut-off point for the definition of renal insufficiency. ${ }^{21}$ In a retrospective review of 938 patients with stable renal insufficiency, the overall incidence of CIN was $6.1 \%$, while the incidence was $4.4 \%$, $10.5 \%$ and $10.0 \%$ in patients whose eGFR was $45-60$, $30-45$ and $\leq 30 \mathrm{~mL} / \mathrm{min}$, respectively. ${ }^{30}$ Hence special care should be taken with patients with renal insufficiency. 
A Study

ID
Events, Events, \%

OR $(95 \% \mathrm{Cl}) \quad$ Bicarbonate Saline Weight

$\begin{array}{llll}1.00(0.06,16.24) & 1 / 88 & 1 / 88 & 7.21\end{array}$

$\begin{array}{llll}0.30(0.03,3.05) & 1 / 30 & 3 / 29 & 21.52\end{array}$

$\begin{array}{llll}1.03(0.06,16.65) & 1 / 108 & 1 / 111 & 7.13\end{array}$

$\begin{array}{llll}1.59(0.26,9.80) & 3 / 71 & 2 / 74 & 13.69\end{array}$

$\begin{array}{llll}0.51(0.05,5.63) & 1 / 175 & 2 / 178 & 14.39\end{array}$

$\begin{array}{llll}1.01(0.06,16.21) & 1 / 250 & 1 / 252 & 7.24\end{array}$

$\begin{array}{llll}0.33(0.01,8.20) & 0 / 72 & 1 / 72 & 10.87\end{array}$

$\begin{array}{llll}1.98(0.36,10.93) & 4 / 193 & 2 / 189 & 14.44\end{array}$

$\begin{array}{lll}5.23(0.25,110.60) & 2 / 87 & 0 / 89\end{array} 3.51$

$\begin{array}{llll}\text { (Excluded) } \quad 0 / 52 & 0 / 51 & 0.00\end{array}$

$\begin{array}{llll}\text { (Excluded) } & 0 / 36 & 0 / 36 & 0.00\end{array}$

$\begin{array}{llll}\text { (Excluded) } & 0 / 78 & 0 / 77 & 0.00\end{array}$

$\begin{array}{llll}\text { (Excluded) } \quad 0 / 30 & 0 / 29 & 0.00\end{array}$

$\begin{array}{llll}\text { (Excluded) } \quad 0 / 151 & 0 / 150 & 0.00\end{array}$

$\begin{array}{llll}\text { (Excluded) } & 0 / 60 & 0 / 59 & 0.00\end{array}$

$\begin{array}{llll}\text { (Excluded) } & 0 / 61 & 0 / 59 & 0.00\end{array}$

$\begin{array}{llll}\text { (Excluded) } & 0 / 267 & 0 / 281 & 0.00\end{array}$

$\begin{array}{llll}1.08(0.52,2.25) & 14 / 1809 & 13 / 1824 & 100.00\end{array}$
B Study

ID
OR $(95 \% \mathrm{Cl}) \quad$ Bicarbonate Saline Weight

$0.18(0.01,3.92) \quad 0 / 30 \quad 2 / 29 \quad 11.25$

$1.02(0.20,5.11) \quad 3 / 175 \quad 3 / 178 \quad 13.16$

$1.35(0.30,6.09) \quad 4 / 250 \quad 3 / 252 \quad 13.23$

$0.62(0.10,4.01) 2 / 30 \quad 3 / 29 \quad 12.82$

$0.85(0.28,2.58) 6 / 151 \quad 7 / 150 \quad 30.36$

$0.11(0.01,2.13) \quad 0 / 44 \quad 4 / 48 \quad 19.18$

$\begin{array}{llll}\text { (Excluded) } \quad 0 / 72 & 0 / 72 & 0.00\end{array}$

$\begin{array}{llll}\text { (Excluded) } \quad 0 / 36 & 0 / 36 & 0.00\end{array}$

(Excluded) $\quad 0 / 78 \quad 0 / 77 \quad 0.00$

$\begin{array}{llll}\text { (Excluded) } \quad 0 / 193 & 0 / 189 & 0.00\end{array}$

(Excluded) $\quad 0 / 61 \quad 0 / 59 \quad 0.00$

(Excluded) $\quad 0 / 159 \quad 0 / 161 \quad 0.00$

$0.69(0.36,1.32) \quad 15 / 1279 \quad 22 / 1280 \quad 100.00$

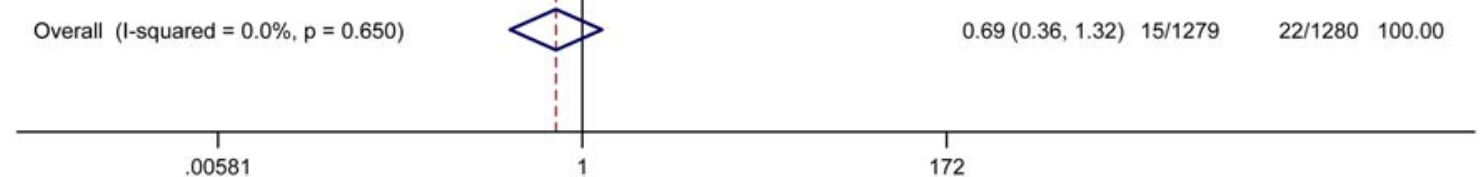

Figure 3 (A) The forest plot of the requirement for dialysis. (B) The forest plot of mortality ORs.

Various mechanisms have been proposed to explain how sodium bicarbonate administration prevents CIN. ${ }^{31} 32$ One suggestion is that sodium bicarbonate makes tubular urine more alkaline, thus attenuating free radical formation and peroxide injury. ${ }^{28}$ Oxygen free radicals and peroxide are usually generated in acidic conditions, and so sodium bicarbonate infusion could increase the $\mathrm{pH}$ of local renal tissue to neutral or slightly alkaline, thereby reducing the production of free radicals and peroxide.
Merten et $a l^{19}$ first introduced the administration of sodium bicarbonate at a concentration of $154 \mathrm{mmol} / \mathrm{L}$ to prevent CIN. In our study, the hydration regimens of 13 trials $^{9-17}$ 19-21 33 were similar to the Merten protocol. Although most previous systematic reviews and relevant meta-analyses demonstrated that sodium bicarbonate infusion could decrease the incidence of CIN,${ }^{25}{ }^{26}{ }^{34-42}$ secondary clinical endpoints as diverse as renal replacement therapy and mortality were not improved. Furthermore, a 
Figure 4 The influence of an individual study on the overall estimates.
Meta-analysis estimates, given named study is omitted oEstimate

I Upper CI Limit

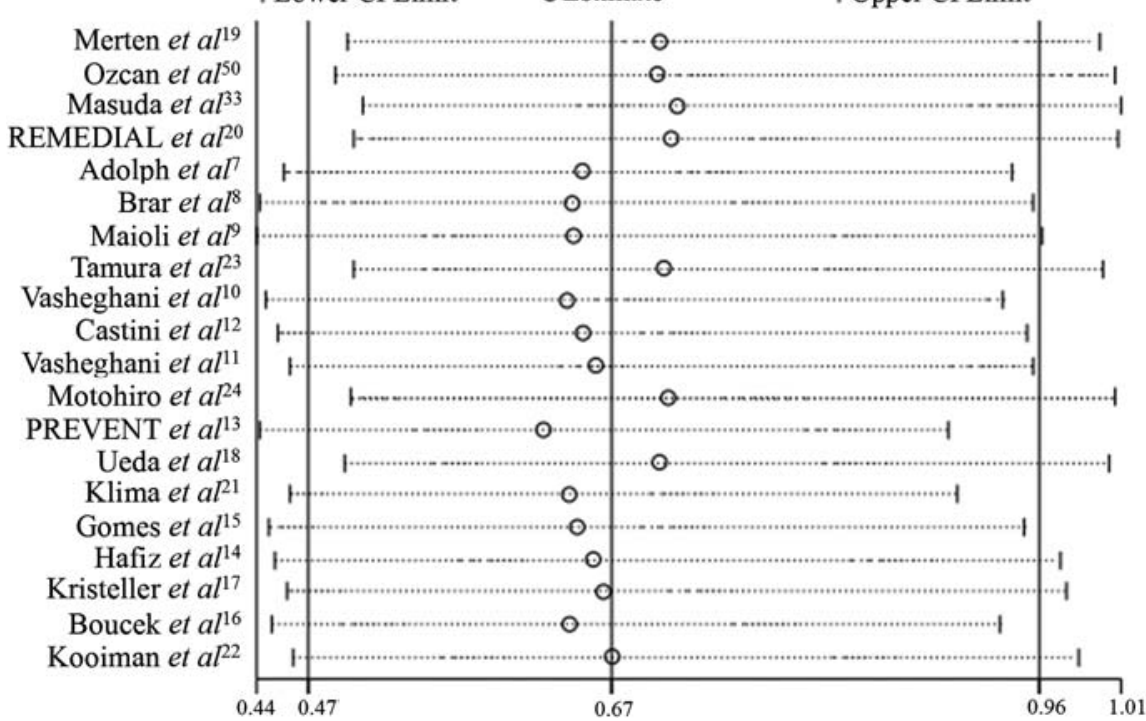

patients undergoing emergency procedures compared with those undergoing elective procedures. However, the exact mechanism by which sodium bicarbonate results in a decrease incidence of CIN remains unknown; perhaps it is related to the method of administration and dosage. Similarly, sodium bicarbonate was more beneficial in patients who received low-osmolar contrast agents. ${ }^{45}$ However, since a significantly fewer number of patients received iso-osmolar contrast media $(n=1189)$ compared with those receiving low-osmolar contrast media $(n=2823)$, the main reason for the better effect of sodium bicarbonate was difficult to determine.

Although the use of NAC has been reported to reduce the incidence of CIN in many studies, the definitive effect of NAC has not yet been established. A number of trials and meta-analyses indicated that the combination of sodium bicarbonate and NAC is superior to either regimen alone in preventing CIN. Three studies ${ }^{20} 44 \quad 47$ included patients who received NAC in both groups after infusion of sodium bicarbonate or saline and the results favoured sodium bicarbonate. The BINARIO study $^{48}$ indicated that hydration with sodium bicarbonate in addition to high-dose NAC in the setting of urgent percutaneous coronary intervention for ST-elevation myocardial infarction was associated with a net clinical benefit. However, Yang et $a t^{27}$ and Thayssen et $a t^{49}$ concluded that the use of NAC did not result in a significant reduction in the incidence of CIN. In our study, only one trial ${ }^{20}$ using NAC was included in the sub-analysis, the effect of which may be overestimated (OR 0.17, $95 \%$ CI 0.04 to $0.79 ; \mathrm{p}=0.024)$. Accordingly, more large-scale and well designed RCTs are warranted to determine whether sodium bicarbonate plus NAC is more useful in preventing CIN than either alone.

Many studies have shown that patients with CIN are at greater risk of renal replacement therapy and death. In fact, almost all the dialysis and death events occurred in

Figure 5 Funnel plot with pseudo 95\% confidence limits. 
patients at high risk of CIN. Therefore, sodium bicarbonate alone would not have been effective in the presence of CIN and underlying disease, such as renal insufficiency and diabetes mellitus, perhaps explaining why we did not find significant differences in dialysis and mortality. However, insufficient power of included RCTs could be another reason. In this meta-analysis, as not all studies described renal replacement therapy, and mortality and sample sizes were relatively small, this issue remains to be explored in the future.

\section{CONCLUSIONS}

Our meta-analysis demonstrates that sodium bicarbonate is superior to saline for the prevention of CIN in patients with pre-existing renal insufficiency undergoing procedures using contrast media. However, use of sodium bicarbonate did not result in obvious benefit in decreasing the requirement for dialysis or reducing mortality. Therefore, larger trials are required to determine the efficacy of sodium bicarbonate in preventing CIN and improving the clinical prognosis of patients with CIN.

\section{Twitter Follow Bin Zhang at @zhangbin}

Contributors BZ, LL and WbC conducted the literature search. BZ wrote the manuscript. LL, $\mathrm{WbC}, \mathrm{ChL}$ and $\mathrm{SxZ}$ reviewed, analysed and helped to write the manuscript. All authors contributed to the conception and design of this study.

Funding This study was supported by grants from the National Scientific Foundation of China (81171329) and the Guangdong Science Foundation (S2011010000790).

Competing interests None.

Provenance and peer review Not commissioned; externally peer reviewed.

Data sharing statement No additional data are available.

Open Access This is an Open Access article distributed in accordance with the Creative Commons Attribution Non Commercial (CC BY-NC 4.0) license, which permits others to distribute, remix, adapt, build upon this work noncommercially, and license their derivative works on different terms, provided the original work is properly cited and the use is non-commercial. See: http:// creativecommons.org/licenses/by-nc/4.0/

\section{REFERENCES}

1. Golshahi J, Nasri H, Gharipour M, et al. Contrast-induced nephropathy: a literature review. J Nephropathol 2014;3:51-6.

2. Humbert A, Kissling S, Teta D. Contrast-induced nephropathy. Rev Med Suisse 2013;9:1222-8.

3. Mohammed NMA, Mahfouz A, Achkar K, et al. Contrast-induced nephropathy. Heart Views 2013;14:106-16.

4. Silva RG, Silva NG, Lucchesi F, et al. Prevention of contrast-induced nephropathy by use of bicarbonate solution: preliminary results and literature review. J Bras Nefrol 2010;32:292-302.

5. Weisbord SD, Chen H, Stone RA, et al. Associations of increases in serum creatinine with mortality and length of hospital stay after coronary angiography. JASN 2006;17:2871-7.

6. Subedi B, Siddique MA, Zaman SM, et al. Contrast induced nephropathy in patients with pre-existing renal impairment undergoing coronary angiogram and percutaneous transluminal coronary angioplasty. Mymensingh Med J 2011;20:270-4.

7. Adolph E, Holdt-Lehmann B, Chatterjee T, et al. Renal Insufficiency Following Radiocontrast Exposure Trial (REINFORCE): a randomized comparison of sodium bicarbonate versus sodium chloride hydration for the prevention of contrast-induced nephropathy. Coron Artery Dis 2008;19:413-19.
8. Brar SS, Shen AY, Jorgensen M, et al. Sodium bicarbonate vs sodium chloride for the prevention of contrast medium-induced nephropathy in patients undergoing coronary angiography: a randomized trial. JAMA 2008;300:1038-46.

9. Maioli M, Toso A, Leoncini M, et al. Sodium bicarbonate versus saline for the prevention of contrast-induced nephropathy in patients with renal dysfunction undergoing coronary angiography or intervention. J Am Coll Cardiol 2008;52:599-604.

10. Vasheghani-Farahani A, Sadigh G, Kassaian SE, et al. Sodium bicarbonate plus isotonic saline versus saline for prevention of contrast-induced nephropathy in patients undergoing coronary angiography: a randomized controlled trial. Am J Kidney Dis 2009;54:610-18.

11. Vasheghani-Farahani A, Sadigh G, Ebrahim Kassaian S, et al. Sodium bicarbonate in preventing contrast nephropathy in patients at risk for volume overload: a randomized controlled trial. J Nephrol 2010;23:216.

12. Castini D, Lucreziotti S, Bosotti L, et al. Prevention of contrastinduced nephropathy: a single center randomized study. Clin Cardiol 2010;33:E63-8.

13. Lee SW, Kim WJ, Kim YH, et al. Preventive strategies of renal insufficiency in patients with diabetes undergoing intervention or arteriography (the PREVENT trial). Am J Cardiol 2011;107:1447-52.

14. Hafiz AM, Jan MF, Mori N, et al. Prevention of contrast-induced acute kidney injury in patients with stable chronic renal disease undergoing elective percutaneous coronary and peripheral interventions: Randomized comparison of two preventive strategies. Catheter Cardiovasc Interv 2012;79:929-37.

15. Gomes VO, Lasevitch R, Lima VC, et al. Hydration with sodium bicarbonate does not prevent contrast nephropathy: a multicenter clinical trial. Arq Bras Cardiol 2012;99:1129-34.

16. Boucek $\mathrm{P}$, Havrdova T, Oliyarnyk $\mathrm{O}$, et al. Prevention of contrast-induced nephropathy in diabetic patients with impaired rena function: a randomized, double blind trial of sodium bicarbonate versus sodium chloride-based hydration. Diabetes Res Clin Pract 2013;101:303-8.

17. Kristeller JL, Zavorsky GS, Prior JE, et al. Lack of effectiveness of sodium bicarbonate in preventing kidney injury in patients undergoing cardiac surgery: a randomized controlled trial. Pharmacotherapy 2013;33:710-17.

18. Ueda $H$, Yamada $T$, Masuda $M$, et al. Prevention of contrast-induced nephropathy by bolus injection of sodium bicarbonate in patients with chronic kidney disease undergoing emergent coronary procedures. Am J Cardiol 2011;107:1163-7.

19. Merten GJ, Burgess WP, Rittase RA, et al. Prevention of contrast-induced nephropathy with sodium bicarbonate: an evidence-based protocol. Crit Pathw Cardiol 2004;3:138-43.

20. Briguori C, Airoldi F, D'Andrea D, et al. Renal Insufficiency Following Contrast Media Administration Trial (REMEDIAL) a randomized comparison of 3 preventive strategies. Circulation 2007;115:1211-17.

21. Klima T, Christ A, Marana I, et al. Sodium chloride vs. sodium bicarbonate for the prevention of contrast medium-induced nephropathy: a randomized controlled trial. Eur Heart J 2012;33:2071-9.

22. Kooiman J, Sijpkens YW, de Vries JP, et al. A randomized comparison of 1-h sodium bicarbonate hydration versus standard peri-procedural saline hydration in patients with chronic kidney disease undergoing intravenous contrast-enhanced computerized tomography. Nephrol Dial Transplant 2014;29:1029-36.

23. Tamura A, Goto $\mathrm{Y}$, Miyamoto $\mathrm{K}$, et al. Efficacy of single-bolus administration of sodium bicarbonate to prevent contrast-induced nephropathy in patients with mild renal insufficiency undergoing an elective coronary procedure. Am J Cardiol 2009;104:921-5.

24. Motohiro $\mathrm{M}$, Kamihata $\mathrm{H}$, Tsujimoto $\mathrm{S}$, et al. A new protocol using sodium bicarbonate for the prevention of contrast-induced nephropathy in patients undergoing coronary angiography. Am J Cardiol 2011;107:1604-8.

25. Meier P, Ko DT, Tamura A, et al. Sodium bicarbonate-based hydration prevents contrast-induced nephropathy: a meta-analysis. BMC Med 2009;7:23.

26. Trivedi $H$, Nadella $R$, Szabo A. Hydration with sodium bicarbonate for the prevention of contrast-induced nephropathy: a meta-analysis of randomized controlled trials. Clin Nephrol 2010;74:288-96.

27. Yang K, Liu W, Ren W, et al. Different interventions in preventing contrast-induced nephropathy after percutaneous coronary intervention. Int Urol Nephrol 2014;46:1801-7.

28. Atkins JL. Effect of sodium bicarbonate preloading on ischemic renal failure. Nephron 1986;44:70-4.

29. Andreucci M, Solomon R, Tasanarong A. Side effects of radiographic contrast media: pathogenesis, risk factors, and prevention. Biomed Res Int 2014;2014:741018. 
30. Murakami R, Hayashi H, Sugizaki K, et al. Contrast-induced nephropathy in patients with renal insufficiency undergoing contrast-enhanced MDCT. Eur Radiol 2012;22:2147-52.

31. McCullough PA, Adam A, Becker CR, et al. Risk prediction of contrast-induced nephropathy. Am J Cardiol 2006;98:27-36.

32. Burgess WP, Walker PJ. Mechanisms of contrast-induced nephropathy reduction for saline $(\mathrm{NaCl})$ and sodium bicarbonate (NaHCO3). Biomed Res Int 2014;2014:510385.

33. Masuda M, Yamada T, Mine T, et al. Comparison of usefulness of sodium bicarbonate versus sodium chloride to prevent contrast-induced nephropathy in patients undergoing an emergent coronary procedure. Am J Cardiol 2007;100:781-6.

34. Hogan SE, L'Allier P, Chetcuti S, et al. Current role of sodium bicarbonate-based preprocedural hydration for the prevention of contrast-induced acute kidney injury: a meta-analysis. Am Heart $J$ 2008;156:414-21.

35. Joannidis M, Schmid M, Wiedermann CJ. Prevention of contrast media-induced nephropathy by isotonic sodium bicarbonate: a meta-analysis. Wien Klin Wochenschr 2008;120:742-8.

36. Ho KM, Morgan DJ. Use of isotonic sodium bicarbonate to prevent radiocontrast nephropathy in patients with mild pre-existing renal impairment: a meta-analysis. Anaesth Intensive Care 2008;36:646-53.

37. Navaneethan SD, Singh S, Appasamy S, et al. Sodium bicarbonate therapy for prevention of contrast-induced nephropathy: a systematic review and meta-analysis. Am J Kidney Dis 2009;53:617-27.

38. Brar SS, Hiremath S, Dangas G, et al. Sodium bicarbonate for the prevention of contrast induced-acute kidney injury: a systematic review and meta-analysis. Clin J Am Soc Nephrol 2009;4:1584-92.

39. Kanbay M, Covic A, Coca SG, et al. Sodium bicarbonate for the prevention of contrast-induced nephropathy: a meta-analysis of 17 randomized trials. Int Urol Nephrol 2009;41:617-27.

40. Hoste EA, De Waele JJ, Gevaert SA, et al. Sodium bicarbonate for prevention of contrast-induced acute kidney injury: a systematic review and meta-analysis. Nephrol Dial Transplant 2010;25:747-58.

41. Kunadian V, Zaman A, Spyridopoulos I, et al. Sodium bicarbonate for the prevention of contrast induced nephropathy: a meta-analysis of published clinical trials. Eur J Radiol 2011;79:48-55.
42. Jang JS, Jin HY, Seo JS, et al. Sodium bicarbonate therapy for the prevention of contrast-induced acute kidney injury-a systematic review and meta-analysis. Circ J 2011;76:2255-65.

43. From AM, Bartholmai BJ, Williams AW, et al. Sodium bicarbonate is associated with an increased incidence of contrast nephropathy: a retrospective cohort study of 7977 patients at Mayo Clinic. Clin J Am Soc Nephrol 2008;3:10-18.

44. Recio-Mayoral A, Chaparro M, Prado B, et al. The reno-protective effect of hydration with sodium bicarbonate plus $\mathrm{N}$-acetylcysteine in patients undergoing emergency percutaneous coronary intervention: the RENO Study. J Am Coll Cardiol 2007;49:1283-8.

45. Jo SH, Youn TJ, Koo BK, et al. Renal toxicity evaluation and comparison between visipaque (iodixanol) and hexabrix (ioxaglate) in patients with renal insufficiency undergoing coronary angiography: the RECOVER study: a randomized controlled trial. J Am Coll Cardiol 2006;48:924-30.

46. McCullough PA, Bertrand ME, Brinker JA, et al. A meta-analysis of the renal safety of isosmolar iodixanol compared with low-osmolar contrast media. J Am Coll Cardiol 2006;48:692-9.

47. Mahmoodi K, Sohrabi B, llkhchooyi F, et al. The efficacy of hydration with normal saline versus hydration with sodium bicarbonate in the prevention of contrast-induced nephropathy. Heart Views 2014;15:33.

48. Leone AM, De Caterina AR, Sciahbasi A, et al. Sodium bicarbonate plus $\mathrm{N}$-acetylcysteine to prevent contrast-induced nephropathy in primary and rescue percutaneous coronary interventions: the BINARIO (BIcarbonato e N-Acetil-cisteina nell'infaRto mlocardico acutO) study. Eurolntervention 2012;8:839-47.

49. Thayssen $\mathrm{P}$, Lassen JF, Jensen SE, et al. Prevention of contrast-induced nephropathy with $\mathrm{N}$-acetylcysteine or sodium bicarbonate in patients with ST-segment-myocardial infarction a prospective, randomized, open-labeled trial. Circ Cardiovasc Interv 2014;7:216-24.

50. Ozcan EE, Guneri S, Akdeniz B, et al. Sodium bicarbonate, Nacetylcysteine, and saline for prevention of radiocontrast-induced nephropathy. A comparison of 3 regimens for protecting contrastinduced nephropathy in patients undergoing coronary procedures. A single-center prospective controlled trial. Am Heart $J$ 2007;154:539-54. 